\title{
Pharmacological Modulation of Noradrenergic Arousal Circuitry Disrupts Functional Connectivity of the Locus Ceruleus in Humans
}

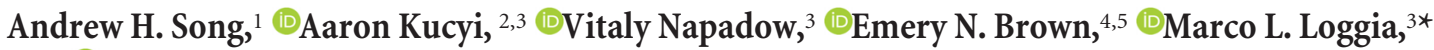 \\ and $\odot$ Oluwaseun Akeju ${ }^{4 \star}$ \\ ${ }^{1}$ Department of Electrical Engineering and Computer Science, Massachusetts Institute of Technology, Cambridge, Massachusetts 02139, ${ }^{2}$ Department of \\ Neurology, Stanford University Medical Center, Stanford, California 94305, ${ }^{3}$ Department of Radiology, Martinos Center for Biomedical Imaging, \\ Massachusetts General Hospital, Harvard Medical School, Charlestown, Massachusetts 02129, ${ }^{4}$ Department of Anesthesia, Critical Care and Pain Medicine, \\ Massachusetts General Hospital, Harvard Medical School, Boston, Massachusetts 02144, and ${ }^{5}$ Harvard-Massachusetts Institute of Technology Division of \\ Health Sciences and Technology, Massachusetts Institute of Technology, Cambridge, Massachusetts 02139
}

State-dependent activity of locus ceruleus (LC) neurons has long suggested a role for noradrenergic modulation of arousal. However, in vivo insights into noradrenergic arousal circuitry have been constrained by the fundamental inaccessibility of the human brain for invasive studies. Functional magnetic resonance imaging (fMRI) studies performed during site-specific pharmacological manipulations of arousal levels may be used to study brain arousal circuitry. Dexmedetomidine is an anesthetic that alters the level of arousal by selectively targeting $\alpha 2$ adrenergic receptors on LC neurons, resulting in reduced firing rate and norepinephrine release. Thus, we hypothesized that dexmedetomidine-induced altered arousal would manifest with reduced functional connectivity between the LC and key brain regions involved in the regulation of arousal. To test this hypothesis, we acquired resting-state fMRI data in right-handed healthy volunteers 18 -36 years of age ( $n=15,6$ males) at baseline, during dexmedetomidine-induced altered arousal, and recovery states. As previously reported, seed-based resting-state fMRI analyses revealed that the LC was functionally connected to a broad network of regions including the reticular formation, basal ganglia, thalamus, posterior cingulate cortex (PCC), precuneus, and cerebellum. Functional connectivity of the LC to only a subset of these regions (PCC, thalamus, and caudate nucleus) covaried with the level of arousal. Functional connectivity of the PCC to the ventral tegmental area/pontine reticular formation and thalamus, in addition to the LC, also covaried with the level of arousal. We propose a framework in which the LC, PCC, thalamus, and basal ganglia comprise a functional arousal circuitry.

Key words: altered arousal; dexmedetomidine; functional connectivity; locus ceruleus; noradrenergic arousal circuit; posterior cingulate cortex

\section{Significance Statement}

Electrophysiological studies of locus ceruleus (LC) neurons have long suggested a role for noradrenergic mechanisms in mediating arousal. However, the fundamental inaccessibility of the human brain for invasive studies has limited a precise understanding of putative brain regions that integrate with the LC to regulate arousal. Our results suggest that the PCC, thalamus, and basal ganglia are key components of a LC-noradrenergic arousal circuit.

\section{Introduction}

The fundamental inaccessibility of the human brain for invasive studies has made in vivo studies of brain arousal circuitry chal- lenging. However, recent advances in functional magnetic resonance imaging (fMRI) acquisition and analyses techniques may

AT007550, R01 AR064367 (V.N.); and by the Department of Anesthesia, Critical Care and Pain Medicine, Massachusetts General Hospital, Boston, Massachusetts.

The authors declare no competing financial interests.

${ }^{*}$ M.L.L. and 0. A. contributed equally to this work.

Correspondence should be addressed to either Dr. Oluwaseun Akeju or Dr. Marco L. Loggia, Massachusetts General Hospital, 55 Fruit St, Gray/Bigelow 444, Boston, MA 02114-2696. E-mail: oluwaseun.akeju@mgh.harvard.edu or marco@nmr.mgh.harvard.edu.

DOl:10.1523/JNEUROSC1.0446-17.2017

Copyright $\odot 2017$ the authors $\quad 0270-6474 / 17 / 376938-08 \$ 15.00 / 0$ 


\section{A LC mask}
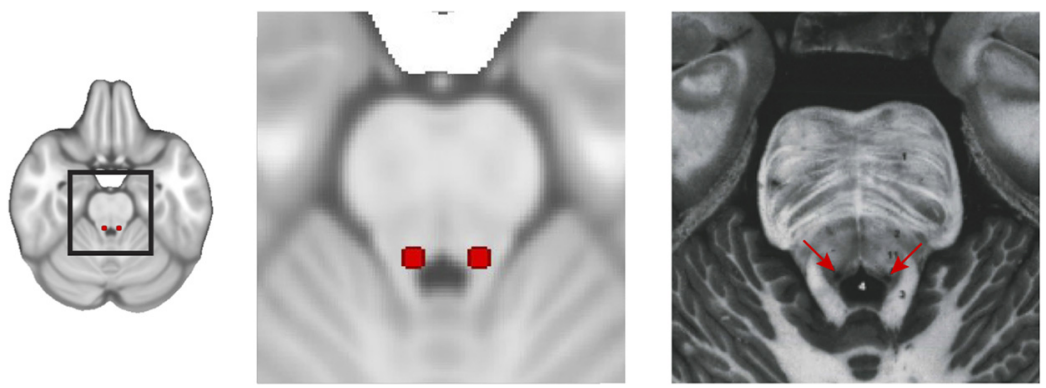

\section{B LC basal connectivity}

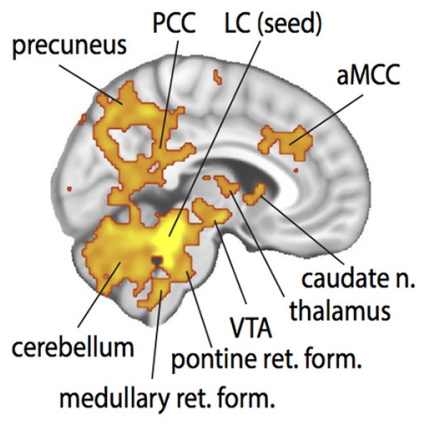

$\mathrm{x}=+6 \mathrm{~mm}$

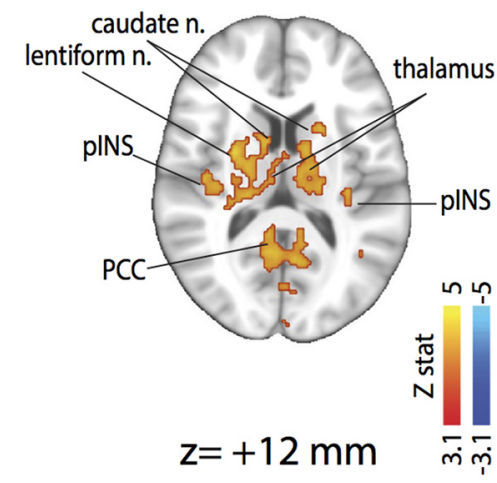

Figure 1. Functional connectivity of the locus ceruleus. $A, \mathrm{LC}$ seed displayed on an axial MNI152 standard volume (left), and a zoomed image of the axial MN1152 standard volume (middle). The location of the LC seed (red arrows) is consistent with the Duvernoy brainstem atlas (right). $\boldsymbol{B}$, Group map $(n=15)$ of the cortical/subcortical connectivity of the LC showed significant functional connectivity with cortical areas ( aMCC, anterior middle cingulate cortex; pINS, posterior insular; precuneus) and subcortical regions (cerebellum; medullary/pontine/mesencephalic reticular formation; caudate nucleus; lentiform nucleus; VTA, ventral tegmental area).

be leveraged to study brainstem circuits in vivo (Sclocco et al., 2017). This is because statistical dependencies between brain regions-of-interest (ROIs) may be used to infer network level mechanisms of brain function. The state-dependent activities of locus ceruleus (LC) neurons have long suggested a role for noradrenergic modulation of arousal (Foote et al., 1980; AstonJones et al., 1991). Anatomically, noradrenergic fibers from the LC project to downstream circuits in the cerebral cortex through the thalamus and basal forebrain, or by direct cortical innervation (Jones and Yang, 1985; Vogt et al., 1987; Kinney et al., 1994; Kinomura et al., 1996; Steriade, 1996; Adams et al., 2000; Parvizi and Damasio, 2003; Buckwalter et al., 2008; Vogt et al., 2008). However, the functional circuit through which the LC regulates arousal remains an open question.

Investigations of LC functional connectivity during altered arousal states (i.e., anesthesia-induced states that result from sitespecific modulation of the LC activity) may enable a principled understanding of noradrenergic arousal circuitry. Dexmedetomidine is the most pharmacologically appealing choice for studying brainstem noradrenergic arousal circuitry. This is because it is different from commonly administered anesthetics and sedative agents, which increase inhibitory postsynaptic currents through $\gamma$ amino-butyric acid receptor targeting. By selectively targeting $\alpha 2 \mathrm{a}$ adrenergic receptors, dexmedetomidine alters the level of arousal by reducing the firing rate of LC neurons, and norepinephrine release (Correa-Sales et al., 1992; Jorm and Stamford, 1993; Chiu et al., 1995). Additionally, downstream of LC neurons, dexmedetomidine may alter the level of arousal by selectively targeting postsynaptic $\alpha 2$ a receptors on nonadrenergic neurons (Buzsáki et al., 1991; Manns et al., 2003; Gilsbach et al., 2009; Hu et al., 2012). Similar to non-rapid eye movement sleep stage 2 (N2), electroencephalogram slow-delta $(0.1-4 \mathrm{~Hz})$ and sleep spindle $(12-16 \mathrm{~Hz})$ oscillations are associated with the dexmedetomidine-induced altered arousal state in humans (Huupponen et al., 2008; Akeju et al., 2014, 2016). Because modulation of noradrenergic circuits is an essential component of $\mathrm{N} 2$ sleep generation and maintenance (E. Brown et al., 2011; R. Brown et al., 2012; Weber and Dan, 2016), dexmedetomidine-induced electroencephalogram oscillations are consistent with laboratory findings that dexmedetomidine targets noradrenergic arousal circuitry (Correa-Sales et al., 1992; Jorm and Stamford, 1993; Chiu et al., 1995).

Recent studies have demonstrated the feasibility of LC functional connectivity studies (Bär et al., 2016; Köhler et al., 2016; Zhang et al., 2016). However, the extent to which the adrenergic arousal circuitry is modulated during altered arousal states has not been investigated. We previously reported that dexmedetomidineinduced altered arousal is associated with decreased regional cerebral blood flow, decreased cerebral metabolic rate of glucose, and functional connectivity changes in regions of the brain that are coincident with the default mode and frontoparietal networks (Akeju et al., 2014). These findings were placed in context with prevailing information-based theories of conscious processing by a graph theoretical analysis which showed that dexmedetomidine-induced altered arousal, similar to other altered arousal states, is associated with decreased local and global efficiency of information processing (Hashmi et al., 2017). In this investigation, we studied the functional connectivity of the LC to elucidate the putative circuitry underlying noradrenergic-mediated arousal states. We hypothesized that dexmedetomidine-induced inhibition of LC neurons would lead to reduced functional connectivity from the LC to key brain regions involved in the regulation of arousal.

\section{Materials and Methods}

Data preprocessing. Details of this study including recruitment, and dexmedetomidine administration were previously reported (Akeju et al., 2014). Briefly, in right-handed healthy volunteers $18-36$ years of age ( $n=15,6$ males), 6 min resting state blood oxygen level-dependent $($ BOLD $) \mathrm{fMRI}(\mathrm{TR} / \mathrm{TE}=3000 / 35 \mathrm{~ms}$, voxel size $=2.3 \times 2.3 \times 3.8 \mathrm{~mm}$, number of slices $=35$ ) were acquired at baseline, dexmedetomidineinduced altered arousal, and recovery. In addition, an MPRAGE structural volume $(\mathrm{TR} / \mathrm{TE}=2100 / 3.24 \mathrm{~ms}$, voxel size $=1 \mathrm{~mm}$ isotropic $)$ was acquired for localization and spatial normalization purposes. Preprocessing of the fMRI data were performed with FSL v.5.0.7. (http://fsl. fmrib.ox.ac.uk) and included slice-timing correction (SLICETIMER), motion-correction (MCFLIRT), brain-extraction (BET), alignment of all runs (FLIRT), fieldmap correction (PRELUDE-FUGUE), registration to MPRAGE (BBREGISTER), and high-pass filtering (cutoff $=0.008$ $\mathrm{Hz}$ ). A one-way repeated-measures ANOVA was performed on the average framewise displacement data to assess whether motion artifacts, not 
Table 1. LC baseline connectivity

\begin{tabular}{|c|c|c|c|c|c|c|}
\hline \multirow[b]{2}{*}{ Label } & \multicolumn{4}{|l|}{ Peak } & \multirow{2}{*}{$\begin{array}{l}\text { Cluster size, } \\
\text { no. of voxels }\end{array}$} & \multirow{2}{*}{$\begin{array}{l}\text { Cluster } \\
p \text { value }\end{array}$} \\
\hline & zstat & $x$ & $y$ & $z$ & & \\
\hline \multicolumn{7}{|l|}{ Positive correlations } \\
\hline RLC & 8.94 & 4 & -36 & -24 & 25821 & 0 \\
\hline Cerebellum & 5.27 & 0 & -58 & -26 & & \\
\hline Pontine ret. form & 5.12 & 4 & -36 & -36 & & \\
\hline L parahippocampal g. & 4.96 & -16 & -12 & -26 & & \\
\hline Medullary ret form & 4.9 & -4 & -36 & -46 & & \\
\hline Precuneus & 4.58 & 2 & -48 & 50 & & \\
\hline L insula & 4.54 & -38 & 4 & -12 & & \\
\hline R putamen & 4.43 & 28 & -2 & 10 & & \\
\hline Rins & 4.37 & 42 & 8 & -10 & & \\
\hline R ventral tegmental area & 4.31 & 4 & -12 & -10 & & \\
\hline R globus pallidus & 4.26 & 20 & -6 & 0 & & \\
\hline L globus pallidus & 4.2 & -22 & -6 & 0 & & \\
\hline L ventral tegmental area & 4.2 & -4 & -14 & -14 & & \\
\hline L putamen & 4.11 & -28 & 0 & -8 & & \\
\hline $\mathrm{R}$ thalamus & 4.1 & 4 & -6 & 6 & & \\
\hline$P C C$ & 4.06 & 2 & -42 & 36 & & \\
\hline L caudate $n$. & 4 & -18 & 12 & 14 & & \\
\hline L thalamus & 3.89 & -12 & -10 & 4 & & \\
\hline R caudate $\mathrm{n}$. & 3.81 & 12 & 4 & 12 & & \\
\hline Occipital pole & 3.68 & -8 & -100 & -80 & & \\
\hline Anterior middle & 4.44 & 2 & 22 & 34 & 1420 & $1.08 \mathrm{E}-13$ \\
\hline \multicolumn{7}{|l|}{ Cingulate cortex } \\
\hline Supplementary motor cortex & 3.85 & 0 & 4 & 56 & & \\
\hline L middle frontal $\mathrm{g}$. & 4.04 & -38 & 32 & 26 & 319 & 0.000114 \\
\hline L middle frontal $\mathrm{g}$. & 3.69 & -34 & 4 & 66 & 163 & 0.00918 \\
\hline L middle frontal $\mathrm{g}$. & 3.63 & -44 & 18 & 32 & 150 & 0.0139 \\
\hline \multicolumn{7}{|l|}{ Negative correlations } \\
\hline n.s. & & & & & & \\
\hline
\end{tabular}

accounted for by the individual level motion regressors, confounded our results. Principal components of the signals with the highest eigenvalues from cortical white matter (WM) mask (5) and CSF mask (5 for the lateral ventricles and 1 for the fourth ventricle) were used to estimate physiological and other spurious sources of noise (Behzadi et al., 2007). To minimize contribution from adjacent gray matter signal, the WM and CSF confound signals were extracted from spatially unsmoothed data using WM and CSF masks that were obtained by segmenting each individual's high-resolution structural image (using FAST in FSL). Six motion parameters computed for the motion-correction step were also included as additional nuisance regressors. As a result, a total of 17 nuisance regressors were included in the GLM. After the extraction of nuisance signals, fMRI data from the brainstem were spatially smoothed with a $3 \mathrm{~mm}$ full-width at halfmaximum (FWHM) for the purpose of extracting the time course of the LC seed (see below), whereas the rest of the brain was smoothed with a $5 \mathrm{~mm}$ FHWM. The decision to use smaller smoothing kernel $(3 \mathrm{~mm})$ for the brainstem was due to the small size of the LC, as well as its proximity to other brainstem structures. All of these steps were conducted in native functional space, and the resulting individual statistical parametric maps were nonlinearly registered to the standard MNI 152 space (FNIRT) for higher-level analyses.

Definition of seed region and functional connectivity analysis. The LC complex was identified similar to a recently published approach (Bär et al., 2016). The LC complex (Fig. $1 A)$ was defined on the left $(4 \times 6 \times 10$ mm centered at MNI-coordinates: $x=-5, y=-34, z=-21)$ and right ROI $(4 \times 6 \times 10 \mathrm{~mm}$ centered at MNI coordinates: $x=7, y=-34, z=$ $-21)$. We performed functional connectivity analyses by correlating the average LC time course against the time courses of all voxels in the brain (controlling for the nuisance regressors), using FLAME (FMRIB's local analysis of mixed effects). At the group level, for the individual condition image (baseline, dexmedetomidine-induced altered arousal, and recovery), a one-sample $t$ test was used and the resulting statistical parametric maps were thresholded by a cluster-forming threshold of $z>3.1$ and a cluster size significance threshold of $p<0.05$. For the contrast image between different conditions (dexmedetomidine-induced altered arousal vs
Table 2. LC connectivity changes

\begin{tabular}{|c|c|c|c|c|c|c|}
\hline \multirow[b]{2}{*}{ Label } & \multicolumn{4}{|l|}{ Peak } & \multirow{2}{*}{$\begin{array}{l}\text { Cluster size, } \\
\text { no. of voxels }\end{array}$} & \multirow{2}{*}{$\begin{array}{l}\text { Cluster } \\
p \text { value }\end{array}$} \\
\hline & zstat & $x$ & $y$ & $z$ & & \\
\hline \multicolumn{7}{|l|}{$\begin{array}{c}\text { Awake }>\text { dexmedetomidine-induced } \\
\text { altered arousal }\end{array}$} \\
\hline L caudate & 4.13 & -12 & 8 & 16 & 4875 & $1.09 \mathrm{E}-14$ \\
\hline $\operatorname{pgACC}$ & 3.7 & -8 & 42 & 12 & & \\
\hline LMFG & 3.66 & -30 & -2 & 48 & & \\
\hline L globus pallidus & 3.56 & -24 & -8 & 0 & & \\
\hline$R$ caudate & 3.55 & 10 & 4 & 14 & & \\
\hline L thalamus & 3.54 & -16 & -22 & 14 & & \\
\hline$R$ thalamus & 3.53 & 4 & -2 & 6 & & \\
\hline Dorsomedial prefrontal cortex & 3.52 & -6 & 32 & 42 & & \\
\hline Ventromedial prefrontal cortex & 3.38 & -6 & 70 & 4 & & \\
\hline L putamen/globus pallidus & 3.19 & -24 & -2 & -2 & & \\
\hline R anterior middle cingulate cortex & 3.15 & 12 & 34 & 18 & & \\
\hline R putamen & 2.62 & 28 & -2 & 12 & & \\
\hline PCC & 3.66 & -8 & -28 & 26 & 1603 & $2.26 \mathrm{E}-06$ \\
\hline L inferior parietal lobule & 3.98 & -42 & -52 & 38 & 1562 & $3.04 \mathrm{E}-06$ \\
\hline L frontal pole & 3.69 & -32 & 40 & 12 & 742 & 0.00247 \\
\hline \multicolumn{7}{|l|}{$\begin{array}{l}\text { Dexmedetomidine-induced } \\
\text { altered arousal }>\text { awake }\end{array}$} \\
\hline Cerebellum & 4.98 & -4 & -42 & -18 & 1924 & $2.38 \mathrm{E}-07$ \\
\hline Dorsal pons & 4.13 & -10 & -32 & -26 & & \\
\hline Pontine grey & 3.14 & 0 & -26 & -26 & & \\
\hline R inferior temporal g. & 3.82 & 50 & -24 & -20 & 963 & 0.00034 \\
\hline R hippocampus & 3.62 & 38 & -24 & -14 & & \\
\hline R superior temporal sulcus & 3.6 & 52 & -12 & -14 & & \\
\hline R temporal pole & 3.38 & 50 & 16 & -12 & & \\
\hline Rinsula & 2.9 & 44 & 6 & -10 & & \\
\hline \multicolumn{7}{|l|}{$\begin{array}{l}\text { Recovery }>\text { dexmedetomidine-induced } \\
\text { altered arousal }\end{array}$} \\
\hline L putamen & 3.94 & -24 & -6 & 4 & 2811 & $3.87 \mathrm{E}-09$ \\
\hline L globus pallidus & 3.81 & -24 & -6 & 2 & & \\
\hline L caudate $n$. & 3.29 & -16 & 14 & 16 & & \\
\hline L thalamus & 3.21 & -18 & -14 & 8 & & \\
\hline LS2 & 3.08 & -48 & -38 & 20 & & \\
\hline $\mathrm{PCC}$ & 3.05 & 8 & -30 & 32 & 849 & 0.00176 \\
\hline R caudate $n$. & 3.45 & 18 & -4 & 20 & & \\
\hline R putamen & 3 & 28 & -14 & 12 & & \\
\hline R globus pallidus & 2.9 & 16 & 4 & 0 & & \\
\hline R thalamus & 2.62 & 4 & -2 & 6 & & \\
\hline
\end{tabular}

baseline, recovery vs dexmedetomidine-induced altered arousal), a paired $t$ test was used. To increase our sensitivity to detect signals in these higher-order contrasts, the resulting statistical parametric maps were thresholded with a cluster-forming threshold of $z>2.3$ and a cluster size significance threshold of $p<0.05$. A conjunction mask across both contrasts was created to identify regions exhibiting connectivity that covaried with arousal state. This conjunction mask helped to make clear the regions demonstrating both a reduction in connectivity to LC between baseline and the altered arousal state, as well as an increase in connectivity to LC from the altered arousal state to recovery. Because this method identified the posterior cingulate cortex (PCC), which we have previously shown to be key region in dexmedetomidine-induced altered arousal (Akeju et al., 2014), we further explored how dexmedetomidine affected the functional connectivity to this specific PCC region, using the methods described above for functional connectivity analyses of the LC.

\section{Results}

\section{LC connectivity covaried with the level of arousal}

Consistent with previously published results (Bär et al., 2016), the LC was functionally connected to a large set of cortical and subcortical regions including the bilateral cerebellar region, reticular formation, ventral tegmental area, thalamus, caudate nuclei, precuneus, PCC, and anterior middle cingulate cortex (Fig. 1B; 


\section{LC}

\section{A Awake vs. dexmedetomidine-induced altered arousal}
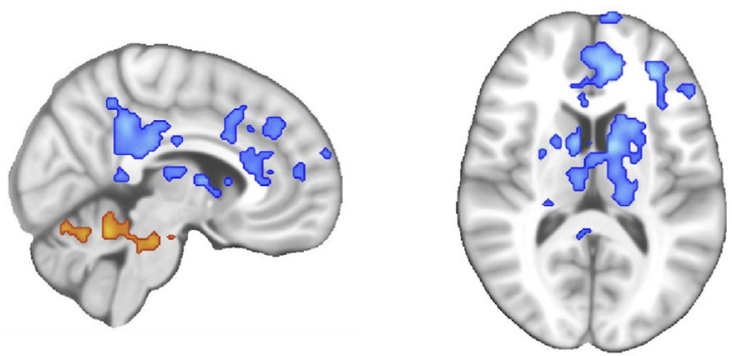

B Recovery vs. dexmedetomidine-induced altered arousal
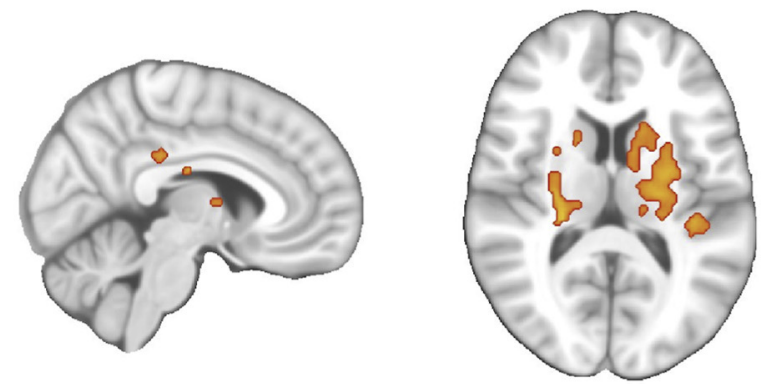

\section{Overlap}

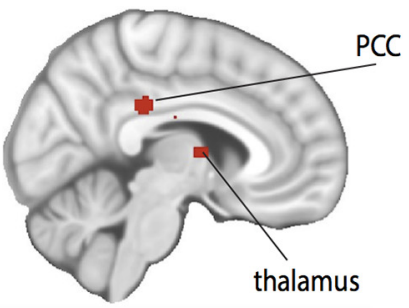

$\mathrm{x}=+6 \mathrm{~mm}$

\section{Illustrative brain regions}

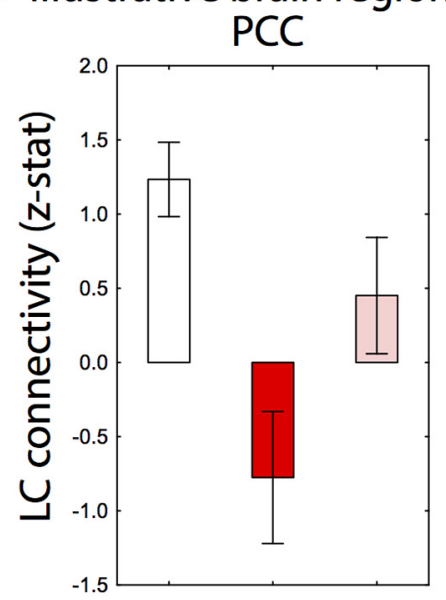

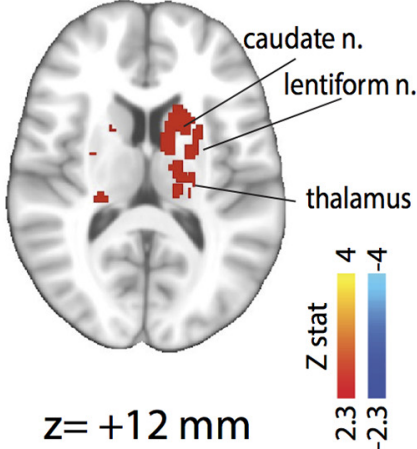

L thalamus

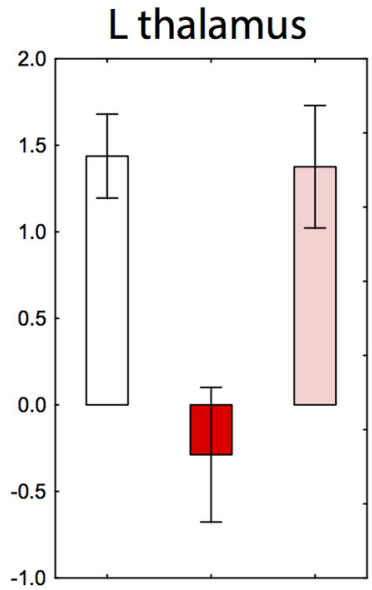

Figure 2. Functional connectivity differencemaps of the locus ceruleus.A,A comparison of $L C$ functional connectivity during dexmedetomidineinduced altered arousal versusbaseline showed cortical areas (aMCC, anteriormiddlecingulate cortex; PCC; precuneus) withreduced connectivity and subcortical areas (cerebellum; pontine reticularformation; ventral tegmental area, VTA) with increased connectivity. B, A comparison of LCfunctional connectivity during the recovery versus dexmedetomidine-induced altered arousal showed cortical areas (dorsal PCC; pINS, posterior insular) and subcortical areas (thalamus; caudate; lentiform nucleus) with increased connectivity. C, Overlap of brain regions with changes that that covaried with the level of arousal (PCC; thalamus; caudate; lentiform). D, LC functional connectivity to the PCC and left thalamus during baseline (white), dexmedetomidine-induced altered arousal (red), and recovery (pink). Errors bars reflect standard deviation.

Table 1). Framewise displacement data were not significantly different between the altered arousal states $(p=0.07$ one-way repeated-measures ANOVA with Greenhouse-Geisser correction). During the dexmedetomidine-induced altered arousal state, the LC demonstrated heterogeneous changes in connectivity to the rest of the brain (Table 2). LC connectivity was decreased to some regions (thalamus, PCC, precuneus, caudate, anterior middle cingulate cortex, and prefrontal cortex), whereas it was increased to others (e.g., cerebellum, brainstem, left anterior insula and temporal cortices; Fig. 2A; Table 2). However, of all the regions that demonstrated any changes in LC connectivity during the altered arousal state, only those with decreased connectivity revealed an activity pattern that covaried with the arousal state (i.e., demonstrated a change in LC connectivity in the opposite direction during recovery than during the altered arousal state). More specifically, the PCC, thalamus, and caudate, which were disconnected from the LC during the altered arousal state regained connectivity to LC during the recovery state (Fig. 2B). None of the regions that exhibited increased connectivity during the altered arousal state demonstrated decreased connectivity during the recovery state (Fig. $2 B$; Table 2). In sum, the PCC, thalamus, and caudate displayed a connectivity pattern that covaried with the level of arousal (Fig. 2C; Table 2). For illustrative purposes, $z$-statistics for two representative brain regions that covaried with the LC are presented in Figure 2D.

\section{PCC connectivity covaried with the level of arousal}

Because a role for the cortex in conscious awareness has been posited, we further studied the connectivity of the PCC, the only cortical brain region that exhibited a functional connectivity pattern that covaried with the level of arousal (Fig. 2C). At baseline, the PCC was functionally connected to a large set of cortical and subcortical regions (Table 3). During the altered arousal state PCC functional connectivity to the cerebellum, brainstem, thalamus, precuneus, and prefrontal cortex was decreased (Fig. 3A; Table 4). During the recovery state a (partial) recovery of PCC connectivity was observed for subcortical regions: the precuneus, thalamus, ventral tegmental area, and locus ceruleus/pontine reticular formation (Fig. 3B). However, none of the cortical regions with decreased connectivity during altered arousal demonstrated increased connectivity during the recovery state (Fig. $3 C$; Table 
Table 3. PCC baseline connectivity

\begin{tabular}{|c|c|c|c|c|c|c|}
\hline \multirow[b]{2}{*}{ Label } & \multicolumn{4}{|l|}{ Peak } & \multirow{2}{*}{$\begin{array}{l}\text { Cluster size, } \\
\text { no. of voxels }\end{array}$} & \multirow{2}{*}{$\begin{array}{l}\text { Cluster } \\
p \text { value }\end{array}$} \\
\hline & zstat & $x$ & $y$ & $z$ & & \\
\hline \multicolumn{7}{|l|}{ Positive correlations } \\
\hline $\mathrm{PCC}$ & 9.15 & 0 & -34 & 28 & 117784 & 0 \\
\hline R thalamus & 6.92 & 4 & -8 & 4 & & \\
\hline $\begin{array}{l}\text { Dorsomedial prefrontal cortex/ } \\
\text { anterior middle cingulate } \\
\text { cortex }\end{array}$ & 6.7 & 0 & 34 & 32 & & \\
\hline $\mathrm{RIPL}$ & 6.7 & 34 & -74 & 48 & & \\
\hline Ventromedial prefrontal cortex & 6.7 & 2 & 60 & 0 & & \\
\hline LIPL & 6.69 & -44 & -56 & 46 & & \\
\hline Precuneus & 6.48 & -10 & -70 & 34 & & \\
\hline R frontal pole & 6.23 & 18 & 70 & 10 & & \\
\hline R middle frontal $\mathrm{g}$. & 6.16 & 34 & 28 & 46 & & \\
\hline R cerebellum & 6.14 & 42 & -60 & -44 & & \\
\hline L thalamus & 6.09 & -6 & -10 & 4 & & \\
\hline L frontal pole & 6.04 & -14 & 64 & 10 & & \\
\hline L middle frontal g. & 6.01 & -34 & 28 & 38 & & \\
\hline L middle temporal g. & 5.85 & -60 & -16 & -24 & & \\
\hline L caudate $n$. & 5.73 & -10 & 12 & 2 & & \\
\hline L hippocampus & 5.71 & -26 & -24 & -12 & & \\
\hline L cerebellum & 5.63 & -8 & -84 & -28 & & \\
\hline R middle temporal g. & 5.6 & 60 & -14 & -18 & & \\
\hline midbrain & 5.45 & -4 & -28 & -18 & & \\
\hline L globus pallidus & 5.41 & -16 & -8 & -2 & & \\
\hline L insula & 5.37 & -36 & 16 & -10 & & \\
\hline Pons & 5.25 & 2 & -28 & -42 & & \\
\hline R hippocampus & 5.2 & 26 & -22 & -14 & & \\
\hline R caudate $\mathrm{n}$. & 5.15 & 12 & 18 & 0 & & \\
\hline R insula & 5 & 36 & 18 & -10 & & \\
\hline R globus pallidus & 4.68 & 20 & -2 & -6 & & \\
\hline R putamen & 4.67 & 20 & 14 & -6 & & \\
\hline L putamen & 4.61 & -28 & 6 & -8 & & \\
\hline Roccipital pole & 4.58 & -18 & -100 & -16 & & \\
\hline L occipital pole & 4.47 & 16 & -98 & -14 & & \\
\hline LS2 & 4.08 & -60 & -26 & 16 & & \\
\hline RS2 & 3.82 & 46 & -32 & 26 & & \\
\hline \multicolumn{7}{|l|}{ Negative correlations } \\
\hline WM & 4.6 & -34 & -50 & 8 & 180 & 0.025 \\
\hline
\end{tabular}

4). For illustrative purposes, $z$-statistics for two representative brain regions that covaried with the PCC are presented in Figure 2D.

\section{Discussion}

In this investigation, we studied the functional connectivity (during baseline, dexmedetomidine-induced altered arousal, and recovery) of the LC, an arousal-promoting center that is located in the pons. Our major finding was that functional connectivity of the LC to the PCC, thalamus, and basal ganglia covaried with the level of arousal. We also studied the functional connectivity of the PCC, the only cortical area that exhibited arousal-dependent functional connectivity to the LC. We found that this specific PCC region became functionally disconnected from subcortical and cortical brain regions during dexmedetomidine-induced altered arousal. Recovery from dexmedetomidine-induced altered arousal was only associated with increased PCC connectivity to subcortical regions (i.e., thalamus, LC).

During the dexmedetomidine-induced altered arousal state, the LC exhibited increased connectivity to the brainstem and decreased connectivity to the cortex. We suggest that increased brainstem connectivity during the altered state of arousal reflects coupling of major brainstem arousal circuits. Functional coupling may result from gamma amino butyric acid- and galanin-mediated inhibition ema-
Table 4. PCC connectivity changes

\begin{tabular}{lllllll}
\hline & Peak & & & $\begin{array}{l}\text { Cluster size, } \\
\text { Label }\end{array}$ & Cluster \\
\cline { 2 - 5 } & zstat & $x$ & $y$ & $z$ & no of voxels & $p$ value \\
\hline
\end{tabular}

Awake $>$ dexmedetomidine-induced altered arousal

R thalamus

$\mathrm{L}$ thalamus

Pons/midbrain

$R$ cerebellum

L caudate $n$.

$L$ ventral tegmental area

L cerebellum

L globus pallidus

$R$ ventral tegmental area

$R$ hippocampus

R caudate $n$.

L hippocampus

L locus coeruleus

R locus coeruleus

R globus pallidus

$R$ insula

L frontoinsular cortex

$R$ frontal pole

Dorsomedial prefrontal cortex

$\mathrm{L}$ middle frontal $\mathrm{g}$.

L frontal pole

Anterior middle cingulate cortex

$R$ middle frontal $\mathrm{g}$.

Ventromedial prefrontal cortex

$\begin{array}{lllll}5.85 & 6 & -2 & 2 & 27039\end{array}$

$1.91 \mathrm{E}-42$

Pregenual anterior cingulate cortex

RL inferior parietal lobule

$\mathrm{R}$ middle temporal $\mathrm{g}$.

$\mathrm{L}$ middle temporal $\mathrm{g}$.

L inferior parietal lobule

PCC

$\begin{array}{lllll}5.2 & -2 & -6 & 8\end{array}$

$\begin{array}{llll}5.13 & 0 & -24 & -22\end{array}$

$\begin{array}{llll}5.12 & 38 & -70 & -34\end{array}$

$\begin{array}{llll}4.9 & -8 & 10 & 2\end{array}$

$\begin{array}{llll}4.88 & -2 & -22 & -20\end{array}$

$\begin{array}{llll}4.79 & -38 & -66 & -50\end{array}$

$\begin{array}{llll}4.67 & -22 & -4 & -4\end{array}$

$\begin{array}{llll}4.42 & 6 & -16 & -14\end{array}$

$\begin{array}{llll}4.41 & 28 & -22 & -12\end{array}$

$\begin{array}{rrrr}4.06 & 8 & 10 & 2\end{array}$

$\begin{array}{llll}4 & -28 & -18 & -12\end{array}$

$\begin{array}{llll}3.99 & -6 & -36 & -22\end{array}$

$\begin{array}{llll}3.97 & 6 & -36 & -26\end{array}$

$\begin{array}{lllll}3.7 & 26 & -16 & -4\end{array}$

$\begin{array}{llll}3.55 & 42 & 10 & -12\end{array}$

$\begin{array}{llll}3.23 & -34 & 14 & 12\end{array}$

$\begin{array}{lllll}4.83 & 38 & 44 & 30 & 10926\end{array}$

$\begin{array}{lrrr}4.6 & 0 & 40 & 38\end{array}$

$\begin{array}{llll}4.21 & -40 \quad 22 & 44\end{array}$

$\begin{array}{llll}4.19 & -48 & 48 & 12\end{array}$

$\begin{array}{llll}3.96 & 6 & 32 & 32\end{array}$

$\begin{array}{llll}3.86 & 46 & 16 & 52\end{array}$

$\begin{array}{llll}3.47 \quad 4 \quad 50 & -6\end{array}$

$\begin{array}{llll}3.15 & 2 & 38 & 2\end{array}$

$\begin{array}{rrrrr}4.16 & 58 & -46 & 32 & 2179\end{array}$

$\begin{array}{llll}3.64 & 64 & -44 & 0\end{array}$

$\begin{array}{lllll}3.67 & -50 & -62 & 0 & 689\end{array}$

$\begin{array}{llll}3.43 & -40 & -66 & 32\end{array}$

Recovery $>$ dexmedetomidine-induced altered arousal

$R$ thalamus

L thalamus

L hippocampus

L caudate nucleus

R parahippocampal g.

$\begin{array}{lllll}4.15 & 0 & -38 & 44 & 641\end{array}$

$641 \quad 0.0173$

Pons

Ventral tegmental area

R hippocampus

L locus coeruleus

R locus coeruleus

Anterior middle cingulate cortex

Paracentral lobule

Supplementary motor area

R planum temporale

R inferior parietal lobule

$\begin{array}{rrrrr}4.48 & 6 & -26 & 8 & 3193\end{array}$

8.52E-09

$\begin{array}{llll}4.37 & -2 & -16 & 6\end{array}$

$\begin{array}{llll}4.09 & -18 & -20 & -18\end{array}$

$\begin{array}{llll}3.83 & -8 & 2 & 10\end{array}$

$\begin{array}{llll}3.41 & 18 & -28 & -14\end{array}$

$\begin{array}{llll}3.39 & -4 & -32 & -38\end{array}$

$\begin{array}{llll}2.83 & 4 & -18 & -12\end{array}$

$\begin{array}{llll}2.74 & 28 & -30 & -12\end{array}$

$\begin{array}{lllll}2.58 & -6 & -36 & -24\end{array}$

$\begin{array}{llll}2.54 & 6 & -38 & -26\end{array}$

$\begin{array}{rrrr}4.13 & -6 & 2 & 32\end{array}$

$\begin{array}{llll}3.08 & -2 & -10 & 68\end{array}$

$2.74 \quad 0 \quad-30 \quad 62$

$\begin{array}{llll}3.87 & 56 & -26 & 12\end{array}$

$\begin{array}{llll}3.49 & 52 & -40 & 36\end{array}$

$\mathrm{R}$ parietal operculum

2.8

1893

6.79E-06

1022

0.00151

nating from the preoptic area or through a complex network of neuronal interactions (Weber and Dan, 2016). A consequence of functionally coupled brainstem arousal circuitry during altered states of arousal is the significant loss of excitatory cortical inputs. Thus, increased LC-brainstem functional connectivity and decreased LC-thalamic/cortical functional connectivity may reflect brainstem-mediated reduction of cortical activation.

Evidence for the posterior cingulate cortex as a cortical hub mediating consciousness

We previously reported that dexmedetomidine-induced altered arousal is associated with decreased regional cerebral blood flow, 


\section{PCC}

\section{A Awake vs. dexmedetomidine-induced altered arousal}
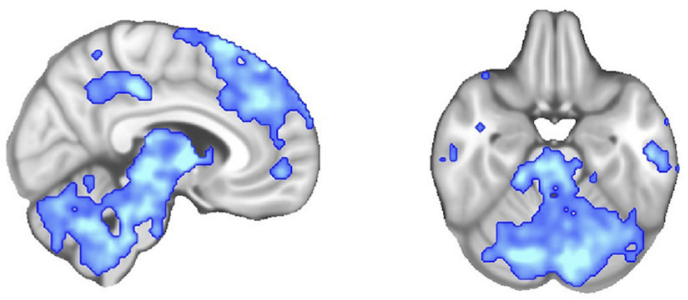

\section{B Recovery vs. dexmedetomidine-induced altered arousal}
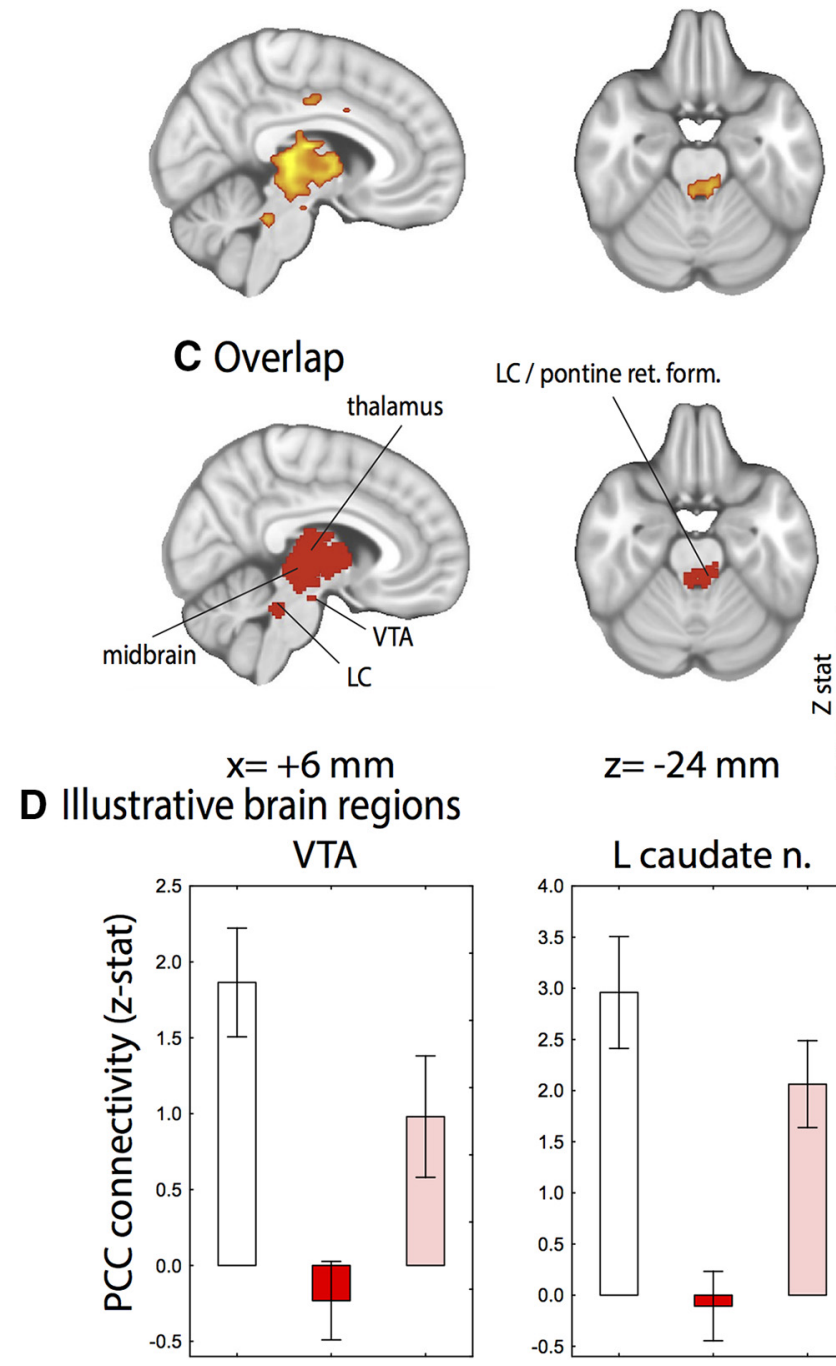

$\mathrm{LC} /$ pontine ret. form.
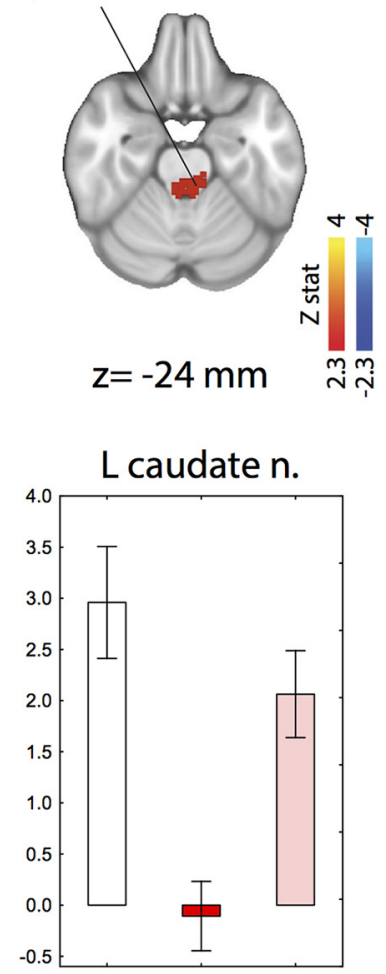

Figure 3. Functional connectivity difference maps of the PCC.A, A comparison of PCC functional connectivity during dexmedetomidineinduced altered arousal versus baseline showed cortical areas (IPL, inferior parietal lobules; prefrontal cortex; precuneus) and subcortical areas (cerebellum; medullary/pontine/mesencephalic reticular formation; thalamus; VTA, ventral tegmental area) with increased connectivity. $\boldsymbol{B}, A$ comparison of PCC functional connectivity during the recovery versus dexmedetomidine-induced altered arousal showed cortical areas (middle cingulate cortex) and subcortical areas (thalamus; pontine/mesencephalic reticular formation including the locus ceruleus; VTA) with increased connectivity. C, Overlap of brain regions with changes that that covaried with the level of arousal (thalamus, midbrain, VTA, locus ceruleus). D, PCC functional connectivity to the VTA and left caudate during baseline (white), dexmedetomidine-induced altered arousal (red), and recovery (pink). Errors bars reflect standard deviation.

decreased cerebral metabolic rate of glucose, and decreased thalamic functional connectivity to the PCC (Akeju et al., 2014). In the present report, the PCC was the only cortical brain region that covaried with LC functional connectivity. A recent serendipitous observation strongly suggests that the PCC may be a cortical hub for consciousness. During a neurosurgical procedure that was being performed awake, electrical stimulation of the WM underlying the left PCC reproducibly resulted in transient disconnection of the patient from the external environment (Herbet et al., 2014). Despite decades of electrocortical stimulation mapping in neurosurgery, to our knowledge, disruption of consciousness has never been precipitated by electrical stimulation to any other cortical region.

This interesting finding supports the notion that the brainstem alone may be insufficient to sustain consciousness (Parvizi and Damasio, 2001; Koch et al., 2016). Rather, it is likely that brainstem, hypothalamic, and basal forebrain neurons provide important inputs for enabling consciousness to cortical regions such as the PCC (Moruzzi and Magoun, 1949; Parvizi and Damasio, 2003; Koch et al., 2016; Weber and Dan, 2016). We suggest that dopaminergic arousal circuits may also mediate interactions between brainstem arousal networks and cortical awareness networks involving the PCC. This is because we found that functional connectivity between the PCC and the ventral tegmental area, a brain area where activation of dopaminergic neurons has been demonstrated sufficient to promote arousal from general anesthesia (Solt et al., 2014; Taylor et al., 2016), covaried with the level of arousal.

A mesocircuit model has been proposed to account for transitions across the continuum of disorders of consciousness (Schiff et al., 2007; Giacino et al., 2014). Our results, including the PCC finding, are consistent with this model. In further support of our findings, abnormal structural connectivity between the PCC and the thalamus has been correlated with clinical severity in patients with disorders of consciousness (Fernández-Espejo et al., 2012). We propose a framework in which structural and/or functional disconnection between the thalamus and PCC signifies a disruption of noradrenergic arousal circuitry. This framework is supported by neuroanatomic studies that show noradrenergic neurons in the LC project to thalamic nuclei, which in turn project to the posterior cingulate cortex (Jones and Yang, 1985; Vogt et al., 1987, 2008; Buckwalter et al., 2008). However, future investigations are necessary to clearly delineate the microcircuit dynamics of the noradrenergic arousal circuit we describe in this paper (LC, PCC, thalamus, caudate nucleus). These investigations may enable new insights into clinical states like abulia, an 
altered arousal state that can range from apathy to akinetic mutism, which is associated with bilateral lesions of caudate nuclei (Bhatia and Marsden, 1994).

\section{Limitations}

A limitation of this study is that numerous arousal nuclei are located in close proximity within the brainstem. Thus, our in plane resolution of $2.3 \times 2.3 \mathrm{~mm}$ and FWHM brainstem smoothing of $3 \mathrm{~mm}$ may have yielded results that reflect the contribution of nonadrenergic arousal circuitry. Also, we did not manipulate the level of arousal in a graded manner. Thus, future studies with improved in plane resolution coupled to graded manipulations of the level of arousal are needed. Such studies may also incorporate administration of the $\alpha 2$ receptor antagonist atipamezole, which although not clinically approved for human use, will enable rapid dose-dependent reversal of the LC functional connectivity changes induced by dexmedetomidine. Finally, although the LC complex was identified similar to a recently published approach (Bär et al., 2016), subject-level delineation of the LC may enable more precise insights into noradrenergic arousal circuitry.

Together, our results suggest that the LC, PCC, thalamus, and basal ganglia are key components of a functional noradrenergic arousal circuit. Further, the PCC may serve as a cortical hub that binds multimodal association cortices to mediate higher brain functions such as awareness.

\section{References}

Adams JH, Graham DI, Jennett B (2000) The neuropathology of the vegetative state after an acute brain insult. Brain 123:1327-1338. CrossRef Medline

Akeju O, Loggia ML, Catana C, Pavone KJ, Vazquez R, Rhee J, Contreras Ramirez V, Chonde DB, Izquierdo-Garcia D, Arabasz G, Hsu S, Habeeb K, Hooker JM, Napadow V, Brown EN, Purdon PL (2014) Disruption of thalamic functional connectivity is a neural correlate of dexmedetomidine-induced unconsciousness. Elife 3:e04499. CrossRef Medline

Akeju O, Kim SE, Vazquez R, Rhee J, Pavone KJ, Hobbs LE, Purdon PL, Brown EN (2016) Spatiotemporal dynamics of dexmedetomidineinduced electroencephalogram oscillations. PloS One 11:e0163431. CrossRef Medline

Aston-Jones G, Chiang C, Alexinsky T (1991) Discharge of noradrenergic locus coeruleus neurons in behaving rats and monkeys suggests a role in vigilance. Prog Brain Res 88:501-520. CrossRef Medline

Bär KJ, de la Cruz F, Schumann A, Koehler S, Sauer H, Critchley H, Wagner G (2016) Functional connectivity and network analysis of midbrain and brainstem nuclei. Neuroimage 134:53-63. CrossRef Medline

Behzadi Y, Restom K, Liau J, Liu TT (2007) A component based noise correction method (CompCor) for BOLD and perfusion based fMRI. Neuroimage 37:90-101. CrossRef Medline

Bhatia KP, Marsden CD (1994) The behavioural and motor consequences of focal lesions of the basal ganglia in man. Brain 117:859-876. CrossRef Medline

Brown EN, Purdon PL, Van Dort CJ (2011) General anesthesia and altered states of arousal: a systems neuroscience analysis. Annu Rev Neurosci 34:601-628. CrossRef Medline

Brown RE, Basheer R, McKenna JT, Strecker RE, McCarley RW (2012) Control of sleep and wakefulness. Physiol Rev 92:1087-1187. CrossRef Medline

Buckwalter JA, Parvizi J, Morecraft RJ, van Hoesen GW (2008) Thalamic projections to the posteromedial cortex in the macaque. J Comp Neurol 507:1709-1733. CrossRef Medline

Buzsáki G, Kennedy B, Solt VB, Ziegler M (1991) Noradrenergic control of thalamic oscillation: the role of alpha-2 receptors. Eur J Neurosci 3:222229. CrossRef Medline

Chiu TH, Chen MJ, Yang YR, Yang JJ, Tang FI (1995) Action of dexmedetomidine on rat locus coeruleus neurones: intracellular recording in vitro. Eur J Pharmacol 285:261-268. CrossRef Medline

Correa-Sales C, Rabin BC, Maze M (1992) A hypnotic response to dexme- detomidine, an alpha 2 agonist, is mediated in the locus coeruleus in rats. Anesthesiology 76:948-952. CrossRef Medline

Fernández-Espejo D, Soddu A, Cruse D, Palacios EM, Junque C, Vanhaudenhuyse A, Rivas E, Newcombe V, Menon DK, Pickard JD, Laureys S, Owen AM (2012) A role for the default mode network in the bases of disorders of consciousness. Ann Neurol 72:335-343. CrossRef Medline

Foote SL, Aston-Jones G, Bloom FE (1980) Impulse activity of locus coeruleus neurons in awake rats and monkeys is a function of sensory stimulation and arousal. Proc Natl Acad Sci U S A 77:3033-3037. CrossRef Medline

Giacino JT, Fins JJ, Laureys S, Schiff ND (2014) Disorders of consciousness after acquired brain injury: the state of the science. Nat Rev Neurol 10: 99-114. CrossRef Medline

Gilsbach R, Röser C, Beetz N, Brede M, Hadamek K, Haubold M, Leemhuis J, Philipp M, Schneider J, Urbanski M, Szabo B, Weinshenker D, Hein L (2009) Genetic dissection of alpha2-adrenoceptor functions in adrenergic versus nonadrenergic cells. Mol Pharmacol 75:1160-1170. CrossRef Medline

Hashmi JA, Loggia ML, Khan S, Gao L, Kim J, Napadow V, Brown EN, Akeju O (2017) Dexmedetomidine disrupts the local and global efficiencies of large-scale brain networks. Anesthesiology 126:419-430. CrossRef Medline

Herbet G, Lafargue G, de Champfleur NM, Moritz-Gasser S, le Bars E, Bonnetblanc F, Duffau H (2014) Disrupting posterior cingulate connectivity disconnects consciousness from the external environment. Neuropsychologia 56:239-244. CrossRef Medline

Hu FY, Hanna GM, Han W, Mardini F, Thomas SA, Wyner AJ, Kelz MB (2012) Hypnotic hypersensitivity to volatile anesthetics and dexmedetomidine in dopamine beta-hydroxylase knockout mice. Anesthesiology 117:1006-1017. CrossRef Medline

Huupponen E, Maksimow A, Lapinlampi P, Särkelä M, Saastamoinen A, Snapir A, Scheinin H, Scheinin M, Meriläinen P, Himanen SL, Jääskeläinen S (2008) Electroencephalogram spindle activity during dexmedetomidine sedation and physiological sleep. Acta Anaesthesiologica Scandinavica 52:289-294. CrossRef Medline

Jones BE, Yang TZ (1985) The efferent projections from the reticular formation and the locus coeruleus studied by anterograde and retrograde axonal transport in the rat. J Comp Neurol 242:56-92. CrossRef Medline

Jorm CM, Stamford JA (1993) Actions of the hypnotic anaesthetic, dexmedetomidine, on noradrenaline release and cell firing in rat locus coeruleus slices. Br J Anaesth 71:447-449. CrossRef Medline

Kinney HC, Korein J, Panigrahy A, Dikkes P, Goode R (1994) Neuropathological findings in the brain of Karen Ann quinlan: the role of the thalamus in the persistent vegetative state. N Engl J Med 330:1469-1475. CrossRef Medline

Kinomura S, Larsson J, Gulyás B, Roland PE (1996) Activation by attention of the human reticular formation and thalamic intralaminar nuclei. Science 271:512-515. CrossRef Medline

Koch C, Massimini M, Boly M, Tononi G (2016) Neural correlates of consciousness: progress and problems. Nat Rev Neurosci 17:307-321. CrossRef Medline

Köhler S, Bär KJ, Wagner G (2016) Differential involvement of brainstem noradrenergic and midbrain dopaminergic nuclei in cognitive control. Hum Brain Mapp 37:2305-2318. CrossRef Medline

Manns ID, Lee MG, Modirrousta M, Hou YP, Jones BE (2003) Alpha 2 adrenergic receptors on GABAergic, putative sleep-promoting basal forebrain neurons. Eur J Neurosci 18:723-727. CrossRef Medline

Moruzzi G, Magoun HW (1949) Brain stem reticular formation and activation of the EEG. Electroencephalogr Clin Neurophysiol 1:455-473. CrossRef Medline

Parvizi J, Damasio A (2001) Consciousness and the brainstem. Cognition 79:135-160. CrossRef Medline

Parvizi J, Damasio AR (2003) Neuroanatomical correlates of brainstem coma. Brain 126:1524-1536. CrossRef Medline

Schiff ND, Giacino JT, Kalmar K, Victor JD, Baker K, Gerber M, Fritz B, Eisenberg B, Biondi T, O'Connor J, Kobylarz EJ, Farris S, Machado A, McCagg C, Plum F, Fins JJ, Rezai AR (2007) Behavioural improvements with thalamic stimulation after severe traumatic brain injury. Nature 448 : 600-603. CrossRef Medline

Sclocco R, Beissner F, Bianciardi M, Polimeni JR, Napadow V (2017) Challenges and opportunities for brainstem neuroimaging with ultrahigh field 
MRI. Neuroimage. Advance online publication. Retrieved May 1, 2017. doi: 10.1016/j.neuroimage.2017.02.052. Medline

Solt K, Van Dort CJ, Chemali JJ, Taylor NE, Kenny JD, Brown EN (2014) Electrical stimulation of the ventral tegmental area induces reanimation from general anesthesia. Anesthesiology 121:311-319. CrossRef Medline

Steriade M (1996) Arousal: revisiting the reticular activating system. Science 272:225-226. CrossRef Medline

Taylor NE, Van Dort CJ, Kenny JD, Pei J, Guidera JA, Vlasov KY, Lee JT, Boyden ES, Brown EN, Solt K (2016) Optogenetic activation of dopamine neurons in the ventral tegmental area induces reanimation from general anesthesia. Proc Natl Acad Sci U S A. 113:12826-12831. CrossRef Medline

Vogt BA, Pandya DN, Rosene DL (1987) Cingulate cortex of the rhesus monkey: I. Cytoarchitecture and thalamic afferents. J Comp Neurol 262: 256-270. CrossRef Medline

Vogt BA, Hof PR, Friedman DP, Sikes RW, Vogt LJ (2008) Norepinephrinergic afferents and cytology of the macaque monkey midline, mediodorsal, and intralaminar thalamic nuclei. Brain Struct Funct 212:465-479. CrossRef Medline

Weber F, Dan Y (2016) Circuit-based interrogation of sleep control. Nature 538:51-59. CrossRef Medline

Zhang S, Hu S, Chao HH, Li CS (2016) Resting-state functional connectivity of the locus coeruleus in humans: in comparison with the ventral tegmental area/substantia nigra pars compacta and the effects of age. Cereb Cortex 26:3413-3427. CrossRef Medline 